Д. Д. Цыренов. Экспертно-методическое сопровождение деятельности управленческих команд региональной системы образования

УДК 338.22

DOI 10.18101/2304-4446-2020-2-41-46

\title{
ЭКСПЕРТНО-МЕТОДИЧЕСКОЕ СОПРОВОЖДЕНИЕ ДЕЯТЕЛЬНОСТИ УПРАВЛЕНЧЕСКИХ КОМАНД РЕГИОНАЛЬНОЙ СИСТЕМЫ ОБРАЗОВАНИЯ
}

\author{
(C) Цыренов Даши Дашанимаевич \\ Бурятский государственный университет имени Доржи Банзарова \\ Россия, 670000, г. Улан-Удэ, ул. Смолина, 24a \\ E-mail: dashi555@mail.ru
}

Реализация национальных проектов, в частности в сфере образования, требует формирования эффективных управленческих команд. В методологии общего подхода к проектной деятельности уделяется мало внимания отбору и формированию управленческих команд. Предложенный и обоснованный в статье проект направлен на преодоление указанного недостатка и позволяет достигнуть планируемых результатов в условиях ограниченных временных, трудовых и материальных ресурсов. В статье раскрыты задачи для достижения поставленной цели, а также основополагающие принципы реализации предложенного проекта. Обоснована устойчивость и сформулирована постппроектная деятельность всех заинтересованных сторон в региональной системе образования. Выявлены и сгруппированы основные потенциальные риски, которые могут возникнуть в ходе реализации проекта, включая и эпидемиологический риск, связанный с распространением коронавируса. Обоснован социальноэкономический эффект от реализации предложенного проекта.

Ключевые слова: управленческая команда; система образования; проектный подход; экспертно-методическое сопровождение; эффективность управления.

\section{Для цитирования}

Цыренов Д. Д. Экспертно-методическое сопровождение деятельности управленческих команд региональной системы образования // Вестник Бурятского государственного университета. Экономика и менеджмент. 2020. № 2. С. 41-46.

В последние годы в системе государственного и муниципального управления активно внедряется проектное управление [2]. Существующие стандарты и методические рекомендации по проектному менеджменту подробно описывают организационно-технологические вопросы разработки проектов [1]. Однако организация проектных команд, механизмы и способы их формирования рассматриваются только с технической точки зрения, а зачастую воспринимаются как имманентно присущие любому проекту. Вместе с тем результаты внедрения проектов зависят именно от эффективности формирования самой проектной команды и постоянной работы с ней.

Иерархическая, линейно-функциональная система управления, большая загруженность управленческого персонала текущей работой препятствуют реализации лидерских и командных практик в сфере образования. Существует разрыв между текущей системой подготовки кадров (содержание программ, процедура отбора, управленческие модели и т.д.) и современными требованиями рынка труда, а также индивидуальной карьерной траекторией. 
В Республике Бурятия управленческий корпус сферы образования составляет 440 директоров образовательных организаций, 829 заместителей директора. Существует кадровый резерв на управленческие должности, однако зачисление и пребывание в этом резерве носит формализованный, стандартный характер, который наблюдается в целом в бюджетной сфере. Целенаправленная кадровая работа по профессиональному развитию резерва зачастую не проводится.

С методологической и практической точек зрения актуально исследование механизмов и инструментов формирования эффективных проектных команд в образовательной системе региона. Это необходимо в условиях низкого качества управления, характеризующегося часто понятиями «ручное управление», «управление по поручениям» или «устранение ошибок и просчетов». Поэтому изучение оценки качества программ в сфере дополнительного профессионального образования, создание Центра подбора и развития управленческих компетенций персонала, где будет проводиться отбор кандидатов, диагностика управленческих компетенций и выстраивание дальнейшей траектории профессионального роста участников, апробация и обучение управленческих команд региона проектному управлению являются необходимостью. Внедрение проектного подхода является одной из ключевых задач совершенствования всей системы государственного и муниципального управления в РФ, в том числе и в образовательной среде, включая и отдельные образовательные организации для реализации национальных проектов.

Вопросами теоретического осмысления и прикладного внедрения эффективных управленческих команд занимаются, например, НИУ ВШЭ, РАНХиГС и РЭУ им. Г. В. Плеханова. Так, РАНХиГС реализует идеи эффективных команд проектного управления в государственном и муниципальном управлении. ВШЭ и РЭУ им. Г. В. Плеханова реализуют идеи эффективной управленческой команды в рамках образовательных программ МВА. Отличительной чертой предлагаемого проекта является ориентация на систему образования, которая является более динамичной, гибкой и изменяющейся.

Целевым назначением предлагаемого проекта является формирование эффективных команд для решения проектных задач в ведущих образовательных организациях региона, а также трансляция опыта в другие организации системы общего образования региона.

Целью является разработка инструментов и механизмов формирования эффективных команд для решения проектных задач, достижения планируемых результатов в условиях ограниченных временных, трудовых и материальных ресурсов. Необходимо создать Центр подбора и развития управленческих компетенций персонала, для того чтобы перспективные, компетентные, инициативные и подготовленные кандидаты умели работать в команде, владели компетенциями в проектном управлении.

Достижение поставленной цели требует реализации комплекса задач:

1) организация дополнительного профессионального образования управленческих команд образовательных организаций разных типов, внедряющих проектный подход, с обеспечением экспертного совета образовательной программы, системы отбора кандидатов для участия в обучении, диагностики управленческих компетенций участников программы, оценки результативности обучения. 
Д. Д. Цыренов. Экспертно-методическое сопровождение деятельности управленческих команд региональной системы образования

2) подготовка, экспертирование и публикация аналитического доклада, включающего в себя оценку механизмов формирования заказа на дополнительное профессиональное образование управленческих кадров в образовании; исследование механизмов оценки качества реализуемых образовательных программ; выявление и обоснование требований к модели подготовки управленческих команд региональных систем общего образования;

3) разработка методических рекомендаций для доработки и дальнейшей реализации программы дополнительного профессионального образования кадрового резерва региональной системы образования, включая предложения по созданию и актуализации образовательных программ и перечня образовательных ресурсов, рекомендации для реализации промежуточного и итогового контроля, а также оценки отсроченных результатов обучения;

4) формирование банка лучших решений, полученных в ходе внедрения проектного управления в образовательных организациях региона.

Достижению целей и ключевых показателей результативности проекта способствуют следующие принципы:

- уникальность создаваемого продукта проектной деятельности, что выражается в освоении участниками проекта компетенций для формирования эффективной команды проекта;

- ограниченность по времени цикла реализации проекта, что предопределяет социальную и командную ответственность участников за результативность в условиях неоднозначности и гетерогенности решаемых задач;

- регулярность и непрерывность экспертно-методического сопровождения деятельности управленческих команд региональной системы образования, что способствует постоянному контакту участников и совершенствованию коммуникативных навыков на каждом этапе жизненного цикла проекта;

- консолидация образовательного и научного потенциала региона, реализация взаимодействия с профессиональными сообществами и организациями социального партнерства;

- удовлетворение образовательных запросов обучающихся и педагогических работников системы общего образования, используя модель персонификации индивидуальной образовательной траектории;

- удовлетворение запросов образовательных организаций региона в части формирования эффективной проектной команды для реализации стратегии развития образовательной организации.

Предлагаемый проект направлен на экспертно-методическое сопровождение деятельности управленческих команд региональной системы образования, обеспечивающее внедрение проектного подхода и в деятельность каждого педагога. Федеральный проект «Учитель будущего» позволяет каждому учителю формировать индивидуальную траекторию своего профессионального и творческого развития, что по своей сути и является индивидуальным проектом каждого педагога, из всей совокупности которых формируется проектный портфель образовательной организации. Эффективные управленческие проектные команды способны организовать работу по удовлетворению образовательных запросов обучающихся и педагогических работников системы общего образования, используя модель персонификации индивидуальной образовательной траектории. 
Экспертно-методическое сопровождение проекта в Республике Бурятия может быть осуществлено ФГБОУ ВО «Бурятский государственный университет имени Доржи Банзарова», который проводит системную работу по повышению квалификации и профессиональной переподготовке педагогических работников Республики Бурятия, Забайкальского края, Монголии на базе Института непрерывного образования вуза (ИНО) [4]. Он был создан в 2009 году на базе факультета повышения квалификации педагогических работников. Ежегодно в ИНО проходит повышение квалификации и профессиональную переподготовку более 2000 педагогических работников. В процессе обучения реализуются современные подходы к образованию педагогов: использование электронной образовательной среды университета, проектная деятельность, интерактивные формы обучения [3].

Устойчивость проекта предполагает формирование комплекса кадровых технологий и личностно-ориентированного подхода к управлению, что должно быть реализовано в следующих направлениях:

- переориентация фокуса с управления процессами на управление людьми и их развитием;

- ориентация не только на решение организационных задач, но и на понимание смысла выполняемых действий;

- выявление взаимосвязи проекта со стратегическим видением руководства организации;

- решение проектных задач в соответствии с запросом общества и его обратной связью, а также требованиями учредителя в лице государства

Постпроектная деятельность образовательных организаций и сформированных эффективных проектных команд связана с формированием биржи «ценных идей» (некий аналог интеллектуального рынка с готовыми проектными решениями для трансляции опыта в другие организации), совершенствованием механизма управления качеством образования на основе проектных критериев оценки, созданием системы управления проектной деятельностью на уровне муниципалитетов и региона в целом.

Созданный Центр подбора и развития управленческих компетенций персонала продолжит отбор кандидатов, диагностику управленческих компетенций и выстраивание дальнейшей траектории профессионального роста участников, апробацию и обучение управленческих команд региона проектному управлению, в том числе и на возмездной основе. Ключевым партнером создаваемого Центра выступит Национальное агентство развития квалификаций, которое позволит создать экзаменационную площадку для независимого подтверждения квалификации управленческих кадров в образовании.

Основные риски, возникающие в процессе реализации предлагаемого проекта, могут быть сгруппированы и преодолены следующим образом (табл. 1) 
Д. Д. Цыренов. Экспертно-методическое сопровождение деятельности управленческих команд региональной системы образования

Таблица 1

Риски проекта и механизмы их преодоления

\begin{tabular}{|c|c|c|}
\hline Виды риска & Характеристика & Пути преодоления \\
\hline Кадровый & $\begin{array}{l}\text { демотивация и низкая компе- } \\
\text { тентность управленческих кад- } \\
\text { ров }\end{array}$ & $\begin{array}{l}\text { тщательный отбор экспертов и } \\
\text { кандидатов для участия в про- } \\
\text { грамме; } \\
\text { разработка системы мотива- } \\
\text { ции участников программы; } \\
\text { информационная поддержка } \\
\text { проекта с участием кандида- } \\
\text { тов, обратная связь с участни- } \\
\text { ками }\end{array}$ \\
\hline Организационный & $\begin{array}{l}\text { нежелание внедрения органи- } \\
\text { зационных и управленческих } \\
\text { изменений в систему общего } \\
\text { образования и } \\
\text { организационную культуру } \\
\text { образовательных организаций }\end{array}$ & $\begin{array}{l}\text { распределение ответственно- } \\
\text { сти между участниками проек- } \\
\text { та, четкое разграничение сфе- } \\
\text { ры деятельности и ответствен- } \\
\text { ность каждого участника; } \\
\text { информационно- } \\
\text { разъяснительная работа в об- } \\
\text { разовательных организациях, } \\
\text { привлечение СМи }\end{array}$ \\
\hline Инновационный & $\begin{array}{l}\text { непринятие изменений, свя- } \\
\text { занных с нововведениями в } \\
\text { образовательном, админи- } \\
\text { стративно-управленческом } \\
\text { процессе }\end{array}$ & $\begin{array}{l}\text { разработка методических ре- } \\
\text { комендаций для внедрения } \\
\text { нововведений и апробация его } \\
\text { на «пилотных» площадках; } \\
\text { публикация аналитических } \\
\text { материалов в СМИ }\end{array}$ \\
\hline Эпидемиологический & $\begin{array}{l}\text { распространение коронавиру- } \\
\text { са COVID-19 }\end{array}$ & $\begin{array}{l}\text { соблюдение требований ме- } \\
\text { дицинских учреждений; } \\
\text { разработка программы отбора, } \\
\text { обучения, сопровождения } \\
\text { кандидатов с помощью ди- } \\
\text { станционных технологий }\end{array}$ \\
\hline
\end{tabular}

Социально-экономический эффект проекта связан с повышением эффективности деятельности общеобразовательных организаций Республики Бурятия, в том числе повышением образовательных результатов обучающихся за счет приобретения руководителями и специалистами образовательных организаций, институтов развития, органов исполнительной власти эффективных управленческих навыков и компетенций, основанных на кооперации и командном подходе к управлению развитием образования.

Сформированная модель эффективной управленческой команды может быть масштабирована в других образовательных организациях общего, дополнительного и профессионального образования, в том числе некоммерческих и иных учреждениях. Целевой заинтересованной аудиторией являются управленческий 
корпус и кадровый резерв в системе образования Республики Бурятия, регионов Дальневосточного федерального округа и ближнего зарубежья.

\section{Литература}

1. Атанов Н. И., Янтранов А. Е. Повышение качества работы региональных институтов государственного управления в Сибирском федеральном округе // Вестник Забайкальского государственного университета. 2015. № 9. С. 88-94.

2. Рубан В. А., Литвиненко М. О. Развитие оценки эффективности государственного управления в Российской Федерации // Вестник Бурятского государственного университета. Экономика и менеджмент. 2018. № 3. С. 61-66.

3. Цыренов Д. Д. Оценка качества профессионального образования с учетом критерия занятости: теория и практика // Проблемы современной экономики. 2011. № 3. C. $315-318$.

4. Янтранов А. Е., Атанов Н. И., Архипов С. В. Университеты как институты регионального развития на примере Республики Бурятия // Вестник Бурятского государственного университета. Экономика и менеджмент. 2019. № 1. С. 62-67.

\section{EXPERT AND METHODOLOGICAL SUPPORT OF MANAGEMENT TEAMS OF THE REGIONAL EDUCATION SYSTEM}

Dashi D. Tsyrenov

Dorzhi Banzarov Buryat State University

24a Smolina St., Ulan-Ude 670000, Russia

E-mail: dashi555@mail.ru

The implementation of national projects, in particular, in the field of education, requires the building of effective management teams. The methods of general approach to project activities pays little attention to the choice and building of management teams. The project proposed in the article is aimed at overcoming this drawback and allows achieving the planned results in the conditions of limited time, labour and financial resources. The article reveals the tasks for achieving this goal, as well as the fundamental principles for the implementation of the proposed project, presents post-project activities of all parties involved in the regional education system. We have identified and grouped the main potential risks that may arise during the implementation of the project, including the epidemiological risk associated with the spread of coronavirus disease. The article provides the rationalization for socioeconomic effect of the implementation of the proposed project.

Keywords: management team; education system; project approach; expert and methodological support; management efficiency. 